\title{
Radiation and energy balance dynamics over young chir pine (Pinus roxburghii) system in Doon of western Himalayas
}

\author{
Nilendu Singh ${ }^{1,4, *}$, Bimal K Bhattacharya ${ }^{2}, \mathrm{M} \mathrm{K} \mathrm{Nanda}^{3}$, \\ Prafulla Soni ${ }^{1}$ and Jai Singh Parihar ${ }^{2}$ \\ ${ }^{1}$ Forest Research Institute, Dehradun 248006 , India. \\ ${ }^{2}$ Space Applications Centre (ISRO), Ahmedabad 380 015, India. \\ ${ }^{3}$ Bidhan Chandra Krishi Viswavidyalaya, Nadia 741 252, India. \\ ${ }^{4}$ Present address: Centre for Glaciology, Wadia Institute of Himalayan Geology, 33 GMS Road, \\ Dehradun 248 011, India. \\ *Corresponding author. e-mail: nilendu_singh@yahoo.com
}

The regional impacts of future climate changes are principally driven by changes in energy fluxes. In this study, measurements on micrometeorological and biophysical variables along with surface energy exchange were made over a coniferous subtropical chir pine (Pinus roxburghii) plantation ecosystem at Forest Research Institute, Doon valley, India. The energy balance components were analyzed for two years to understand the variability of surface energy fluxes, their drivers, and closure pattern. The period covered two growth cycles of pine in the years 2010 and 2011 without and with understory growth. Net short wave and long wave radiative fluxes substantially varied with cloud dynamics, season, rainfall induced surface wetness, and green growth. The study clearly brought out the intimate link of albedo dynamics in chir pine system with dynamics of leaf area index (LAI), soil moisture, and changes in understory background. Rainfall was found to have tight linear coupling with latent heat fluxes. Latent heat flux during monsoon period was found to be higher in higher rainfall year (2010) than in lower rainfall year (2011). Higher or lower pre-monsoon sensible heat fluxes were succeeded by noticeably higher or lower monsoon rainfall respectively. Proportion of latent heat flux to net radiation typically followed the growth curve of green vegetation fraction, but with time lag. The analysis of energy balance closure (EBC) showed that the residual energy varied largely within $\pm 30 \%$ of net available energy and the non-closure periods were marked by higher rainspells or forced clearance of understory growths.

\section{Introduction}

The regional impacts of future climate changes are principally driven by changes in energy fluxes and associated hydrological changes (Rach et al. 2014). The impact of any changes in the energy fluxes and consequent hydrological changes will be significant in energy-limited, mid altitudinal, subtropical western Himalayan forests. Mid-altitudinal (500-3500 m) western Himalayan slopes are known to influence the magnitude of the southwest monsoon by surface heat and moisture fluxes via 'sensible heat driven air pump mechanism' (Boos and Kuang 2010; Wu et al. 2012).

The forests of the mid-altitudinal range are deciduous type of chir pine (Pinus roxburghii) (500-2000 m) and oak (Quercus leucotricophora) $(2000-3500 \mathrm{~m})$ forests. These ecosystems have synchronous, distinct leaf-emergence and leaf-fall seasons (Singh and Singh 1992). Furthermore,

Keywords. Micrometeorology; young chir pine; surface heat fluxes; energy balance closure. 
there are reports of large-scale pine invasions into oaks (Singh and Singh 1992; Singh et al. 2006). This is largely driven by climatic as well anthropogenic factors (GBPIHED 2009). Chir pine being stress tolerant can potentially colonize the disturbed and moisture deficient sites (Singh and Singh 1992), as pines are known to use water efficiently by maintaining delicate water balance at xylem-stomatal level (Ryan and Yoder 1997).

The Himalayan coniferous forest is one of the major terrestrial eco-regions in the Indo-pacific region spread over $3000 \mathrm{~km}$ at length occupying $76,200 \mathrm{~km}^{2}$. The subtropical western Himalayan coniferous chir pine (Pinus roxburghii) forest is spread over about $18,627 \mathrm{~km}^{2}$ and is the most dominant vegetation within the altitudinal range of 500-2000 m. This constitutes about $5.99 \%$ of total forested area of India (FSI 2011). Pine ecosystem may enhance the regional spring time (MarchApril) albedo, as they have the lowest leaf area index (LAI) during this period with needles having a life span of one year (Singh and Singh 1992). Thus, these ecosystems having distinct leafemergence and leaf-fall seasons may exert greater influence on the mean regional energy balance, temperature, and climate as a whole. Furthermore, anthropogenic activities and consequent invasion by early succession shrubs such as Lantana camara are changing the forest surface characteristics very fast and irreversibly (Bhatt et al. 1994; Kimothi et al. 2010; Dobhal et al. 2011). The changes in vegetated land use lead to significant changes in surface albedo, energy balance, as well as surface roughness characteristics in a shorter (daily to seasonal) time scale. Consequently, the energy partitioning as well as water and carbon exchange is likely to change with changing vegetation trends. Thus, the changing surface characteristics are likely to affect the interaction between vegetation and atmosphere thereby influencing local as well as regional climate (Betts 2001; Bonan 2008). The recent summer heat waves, highly variable southwest monsoon (GBPIHED 2009-10) and declining trend in winter rainfall (Rawat 2012) may be some of the consequences of large-scale changes in surface characteristics in this region due to recent urbanization.

The long-term data on energy and water balance in conifers are scanty, particularly in India. Given the climatic importance of the mid-altitudinal Himalayan forest, the present scenario of vegetation shift and changing forest surface characteristics, there is a need to understand the dynamics of surface energy exchange and regulation behavior in water conservative, deciduous coniferous forests. Therefore, the present study focuses on the dynamics of radiation and energy balance behavior over a coniferous vegetative system such as pine, in this region at different time scales through systematic ground measurements. The objectives of this study are:

- to characterize the seasonal variation of radiative and convective heat fluxes at different growth phases of chir pine;

- to assess the degree of energy balance closure in relation to environmental and anthropogenic factors; and

- to find out possible relation between heat flux in pine system and variability in southwest monsoon rainfall.

\section{Study site description}

\subsection{Site characteristics}

The experimental site consisted of a young, growing chir pine plantation (8.5 years old) patch $(400 \mathrm{~m} \times 500 \mathrm{~m})$ within the reserve forest at the Forest Research Institute campus, Dehradun, India $\left(30^{\circ} 20^{\prime} 4^{\prime \prime} \mathrm{N}, 78^{\circ} 00^{\prime} 01^{\prime \prime} \mathrm{E}\right.$, elevation: $\left.640 \mathrm{~m}\right)$. The mean height of the young pines during the study period was $\sim 6.5 \mathrm{~m}$, which was increasing at the rate of $\sim 1.0 \mathrm{~m}$ per year. Mean DBH (diameter at breast height) was $\sim 13.83 \mathrm{~cm}$; it was increasing at the rate of about $1.0 \mathrm{~cm}$ per year. Average crown height was $3.94 \mathrm{~m}$, increasing at the rate of $\sim 0.33 \mathrm{~m}$ per year. The average rooting depth of young pine was about $3 \mathrm{~m}$. The dominant understory species was Lantana camara. The land management practices in this stand usually clear Lantana and other minor species in the post-monsoon period during October-November. The same land management practice was followed in 2010. For understanding and comparing the effects of understory on energy balance and closure, the undergrowths were not cleared in the year 2011 .

\subsection{Climate and soil}

Climatically, the research site is a subtropical system. The mean monthly air temperature was found to vary between $11.5^{\circ}$ and $27^{\circ} \mathrm{C}$ with the lowest in January and the highest during June. The mean monthly relative humidity ranged from $52 \%$ to $85 \%$ with the lowest in April and the highest in August. Minimum and maximum rainfall occurs in the months of November $(\sim 4 \mathrm{~mm})$ and August $(\sim 570 \mathrm{~mm})$, respectively. The bright sunshine hours varied between 4.4 and $9.3 \mathrm{hd}^{-1}$ with minimum during the months of July and August and maximum during the month of May. The monthly mean wind velocity varied between 1.5 and 4.0 $\mathrm{kmh}^{-1}$ with a minimum during the months of November-December and maximum during AprilJune. The mean monthly open pan evaporation 
was found to vary from 1.17 to $7.22 \mathrm{mmd}^{-1}$ with the lowest during December and the highest during the month of May. The mean monthly vapour pressure deficit was found to vary from 3.25 to 27.45 mbar with the lowest during the months of August-September and the highest during April. The number of rainy days was maximum (20) during the months of August and minimum (1) during November-December.

The soil is deeply weathered Mollisols and is $3-8 \mathrm{~m}$ thick. The $\mathrm{pH}$ is acidic ranging from 4.5 to 6.0 , nutrient rich, with a porosity range of $40-60 \%$. The soil texture of the site is sandy clay loam with $35 \%$ sand, $40 \%$ clay, and $25 \%$ silt. The bulk density of the soil is $\sim 1.03$. The soil moisture content of the site ranges from $10 \%$ in peak summer days to above $28 \%$ during rainy season.

\subsection{Experimental details: In situ measurements}

\subsubsection{Micrometeorological observations}

An Indian National Satellite (INSAT) linked micrometeorological tower of $13 \mathrm{~m}$ height (Bhattacharya et al. 2009) was installed within homogenously distributed young pine plantation with a fetch of about $500 \mathrm{~m}$ from all directions (fetch ratio: 1:100) for continuous and automated measurements of radiation components (short wave and long wave), energy, and water balance. The sensors consist of four component net radiometers (at $10 \mathrm{~m}$ ) (NR Lite, Kipp and Zonen, Delft, Netherlands), two-depth (at 0.1 and $0.2 \mathrm{~m}$ ) soil heat flux plates (HFP-01SC, Radiation \& Energy Balance System Inc., USA), three-height (at 4.5, 7.5 and $12.5 \mathrm{~m}$ ) air temperaturerelative humidity (AT-RH) probes with a shielded and aspirated sensor (HMP-45C, Campbell Scientific, Logan, USA), three-height (4.5, 7.5 and $12.5 \mathrm{~m})$ anemometer-vane for wind speed and direction (KDS-131, KEPL, India) and three-depth (0.05, 0.2 and $0.45 \mathrm{~m}$ ) soil thermometers (KDS-031, KEPL, India). A rain gauge of tipping bucket type
(KDS-071, KEPL, India) was placed in open to record rainfall. A programmable 25-channel data logger (DSAWSKM1-W, KEPL, India) automatically stored these data. The data were logged every second and averaged for 30 minutes. In the present study, half-hourly averaged micrometeorological data were analyzed for the 2-year study period from January 2010 to December 2011 covering two growth cycles of the chir pine system.

\subsubsection{Biophysical measurements}

Sampling design: The experimental site was divided into nine sampling quadrats $(10 \mathrm{~m} \times 10 \mathrm{~m})$ : four in the east direction (named EQ1-EQ4), two in the south direction (SQ1 and SQ2), one each in west and north directions (WQ and NQ) and central quadrat (CQ) taking consideration of the direction and space available. CQ is the point where the micrometeorological tower was placed. The sampling design is shown below in figure 1 .

Phenology: The phenology of the growing chir pine was such that it exhibited distinct greening and browning growth stages in a given growth cycle. Digital field photographs taken from all quadrats at weekly interval were analyzed to ascertain the transition dates from one growth stage to another. The time-period from the end of May to end of September exhibited the full green stage characterized by fully green, mature, and elongated needles. During this period, crown was fully green with no traces of brown needles so that total photosynthetic area (computed by mechanical counting of all needles in the crown) was equated with green vegetation fraction (GVF) of one which is $100 \%$. In the first week of October, traces of brown needles began to appear. By the end of October, about $8 \%$ of the needles turned brown. Thus, GVF at the end of October was 0.92. As the plants progressively entered into physiologically dormant stage with the

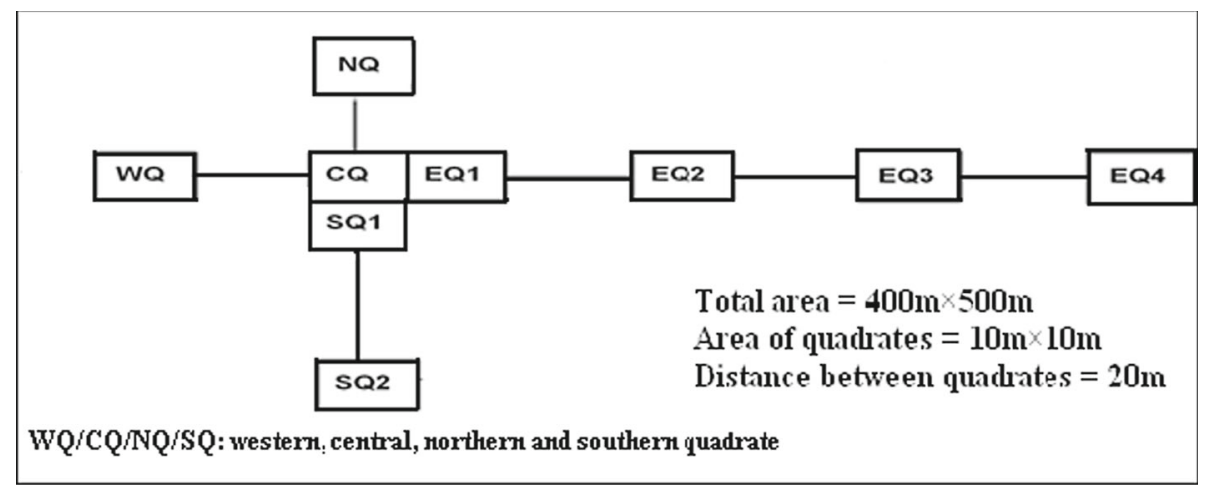

Figure 1. Sampling design for measurements of biophysical properties of young chir pine patch at Forest Research Institute (FRI), Dehradun, India. 
Table 1. Broad categories of phenological stages of growing pine.

\begin{tabular}{ll}
\hline Time period in a year & \multicolumn{1}{c}{ Phenological stages } \\
\hline March to May & Needle elongation and start of greening \\
June to September & Fully-green needles \\
October to December & Start of needle browning \\
January to February & Needle browning and drying \\
\hline
\end{tabular}

approach of winter, the rate of browning increased rapidly. At the end of each month, remaining green needles were counted mechanically and GVF was computed accordingly. By the end of March, about $8-10 \%$ of the needles remained green. GVF at this stage was about 0.17 . The month of March was also characterized by simultaneous emergence of new needle buds (table 1 ).

Leaf Area Index (LAI): The LAI was measured at 10-day interval. We used portable and easy to handle plant canopy analyzer (LAI-2000; Li-Cor, Inc., Lincoln, NE) for measuring LAI. For each quadrat, mean LAI was obtained as average of eight readings (two readings above the canopy and six readings below the canopy in different directions). Every time mean LAI was computed by considering the LAIs of all the quadrats. The usual definition of LAI (one sided leaf area per unit ground area) could not be applied directly to needle-leaved conifers. Therefore, a modified procedure was followed for conifer LAI after Norman and Gower (1990). The LAI for green needles is referred to hereafter as green LAI (GLAI).

\section{Methodology}

\subsection{Radiation balance and net available energy}

The batch processing of micrometeorological station data was carried out using 'Fluxsoft' software, developed at Space Applications Centre (ISRO) in Windows platform on Visual Studio using the protocol developed by Bhattacharya et al. (2009). An IDL (Interactive Data Language) routine was written to convert all half-hourly fluxes into daily averages. Radiation balance components and ground heat fluxes were averaged for 24-hour periods. Ten-day (dekadal) and monthly averages of fluxes were computed from daily averages. The dekadal averages were made to remove unnecessary spikes in the instantaneous and daily averages and to have smooth temporal transition (Verma 1990; Leuning et al. 2012).

The net radiation at the chir pine vegetation surface was computed from the four components of radiation balance as given in equation (1)

$$
R n=R S_{\text {net }}+R L_{\text {net }}
$$

where,

$$
\begin{aligned}
& R S_{\text {net }}=R S \downarrow-R S \uparrow \\
& R L_{\text {net }}=R L \downarrow-R L \uparrow
\end{aligned}
$$

where $R S$ and $R L$ are short wave and long wave radiations respectively. The symbols ' $\downarrow$ ' and ' $\uparrow$ ' represent incoming and outgoing fluxes, respectively. The $R S_{\text {net }}$ and $R L_{\text {net }}$ are net short wave and net long wave radiation fluxes at surface. The net radiation $(R n)$ is partitioned as sensible heat flux $(S H)$, latent heat flux $(L E)$, ground heat flux $(G)$, and metabolic and storage energy in the vegetation canopy $(\Delta H)$.

$$
R n=S H+L E+G+\Delta H .
$$

The storage heat of the canopy is being ignored in seasonal cycle, with the assumption that the amount of energy stored during the heating cycle is released during the cooling cycle in the short heighted, open canopied plantation (Leuning et al. 2012). The amount of metabolic heat is usually negligible as compared to other components.

The net available energy $(Q)$ was computed as:

$$
Q=R n-G \text {. }
$$

\subsection{Sensible (SH) and latent heat (LE) fluxes}

The main tenet of Monin-Obukhov similarity theory (MOST) allows turbulent fluxes of scalars within the surface layer to be related to their vertical gradients of mean concentrations by an eddy diffusivity (Garrat 1992). The eddy diffusivity caused by turbulent mixing is related to the size of the turbulent eddies and is therefore proportional to the distance from the underlying surface or effective surface. The effective surface in case of vegetation canopy of height ' $h$ ' is defined at a height ' $d$ ' above the ground surface where, ' $d$ ' is called zero plane displacement. Under neutral stability condition the wind profile equation above a homogeneous vegetation canopy is thus, expressed as follows (Thom 1975):

$$
\begin{aligned}
u(Z) & =\frac{u_{*}}{k} \ln \left(\frac{z}{z_{0}}\right) \\
\frac{d u}{d z} & =\frac{u_{*}}{k(z-d)}
\end{aligned}
$$


Here, $Z$ is the height of wind measurement above the zero plane displacement, $Z_{0}$ is roughness length, $u_{*}$ is friction velocity, and $k$ is Von-Karman constant $(=0.4)$. The parameters, $d$ and $Z_{0}$ depend upon the aerodynamic roughness of the surface over which measurements are made. The zero plane displacement $(d)$ and roughness length $\left(Z_{0}\right)$ were computed from plant height $(h)$ using simple empirical relations: $d=0.65 \times h$ and $Z_{0}=$ $0.1 \times h$ given by Campbell and Norman (1998). The eddy viscosity was estimated from wind speed and roughness parameters using the logarithmic wind profile equation. The solution of the logarithmic equation is simple under neutral stability condition. However, absolute neutral stability cannot be assumed always because very often, there is a thermal gradient in either direction in the vertical profile within the lower boundary layer. The atmosphere normally becomes stable during night time and unstable during daytime because of substantial heating during daylight hours. Under unstable or stable conditions, the stability parameter, sensible heat flux, and eddy viscosity become auto-correlated. In the present study, stability corrected aerodynamic resistance was determined through iterative method based on MOST.

According to the MOST (Businger et al. 1971; Xu and Qiu 1997; De Bruin et al. 2000), the vertical profiles of wind, temperature, and specific humidity for turbulent flows above a vegetation surface can be expressed as:

$$
\begin{aligned}
& u_{2}-u_{1}=\frac{u_{*}}{s k}\left[\ln \left(\frac{Z_{2}}{Z_{1}}\right)-\Psi_{M}\left(\frac{Z_{2}}{L}\right)+\Psi_{M}\left(\frac{Z_{1}}{L}\right)\right] \\
& \theta_{2}-\theta_{1}=\frac{\theta_{*}}{k}\left[\ln \left(\frac{Z_{2}}{Z_{1}}\right)-\Psi_{H}\left(\frac{Z_{2}}{L}\right)+\Psi_{H}\left(\frac{Z_{1}}{L}\right)\right] \\
& q_{2}-q_{1}=\frac{q_{*}}{k}\left[\ln \left(\frac{Z_{2}}{Z_{1}}\right)-\Psi_{Q}\left(\frac{Z_{2}}{L}\right)+\Psi_{Q}\left(\frac{Z_{1}}{L}\right)\right]
\end{aligned}
$$

In the above expressions, $u=$ wind speed $\left(\mathrm{ms}^{-1}\right)$, $\theta=$ potential temperature $(\mathrm{K}), q=$ specific humidity $\left(\mathrm{g} \mathrm{kg}^{-1}\right), Z=$ height of measurement $(\mathrm{m})$ above the zero plane displacement $[(7.5 \mathrm{~m}-d)$ and $(12.5 \mathrm{~m}-d)$ in the present study. The subscripts, 1 and 2, represent lower and upper heights for the respective parameters in the profile measurement; $\theta_{*}=$ temperature scale, $q_{*}=$ humidity scale and $u_{*}=$ frictional velocity (wind scale); $\Psi=$ universal stability function for momentum (subscript $M$ ), heat (subscript $H$ ) and vapour (subscript $Q$ ); $L=$
Monin-Obukhov similarity length is expressed as follows:

$$
L=\frac{T u_{*}^{2}}{g k \theta_{*}} .
$$

The sensible and latent heat fluxes are expressed as:

$$
\begin{gathered}
S H=-\rho C_{p} \theta_{*} u_{*} \\
L E=-\rho \lambda q_{*} u_{*}
\end{gathered}
$$

where $\rho=$ air density, $T=$ mean absolute temperature, $C p=$ specific heat of air, and $g=$ acceleration due to gravity, and $\lambda=$ latent heat of vaporization of water.

For computation of the stability functions $(\Psi)$ for momentum $(M)$, heat $(H)$ and vapour $(Q)$ in this study, we adopted for unstable conditions the version of the Businger-Dyer flux relationships proposed by Dyer (1974), which read in integrated form as:

$$
\begin{gathered}
\Psi_{M}=2 \ln \left(\frac{1+x}{2}\right)+\ln \left(\frac{1+x^{2}}{2}\right) \\
-2 \tan ^{-1}(x)+\frac{\pi}{2} \\
\Psi_{H}=\Psi_{Q}=2 \ln \left(\frac{1+x^{2}}{2}\right)
\end{gathered}
$$

where,

$$
x=\left(1-16 \frac{Z}{L}\right)^{\frac{1}{4}} .
$$

For stable conditions, we used the equations proposed by Beljaars and Holstag (1991):

$$
\begin{aligned}
-\Psi_{M}=\frac{a Z}{L} & +b\left(\frac{Z}{L}-\frac{c}{d}\right) \exp \left(-\frac{d Z}{L}\right)+\frac{b c}{d} . \\
-\Psi_{H}= & \left(1+\frac{2}{3} \frac{a Z}{L}\right)^{\frac{3}{2}}+b\left(\frac{Z}{L}-\frac{c}{d}\right) \\
& \times \exp \left(-\frac{d Z}{L}\right)+\left(\frac{b c}{d}-1\right)
\end{aligned}
$$

in which $a=1, b=0.667, c=5$ and $d=0.35$ are constants taken as per Beljaars and Holstag (1991).

The computation steps are explained in figure 2. The profile measurement of temperature, humidity, wind speed at the heights 7.5 and $12.5 \mathrm{~m}$ above ground surface were used for the computation process.

The vapour pressure, specific humidity and air density required in MOST were computed from the tower measurements of temperature, relative humidity and air pressure using standard 


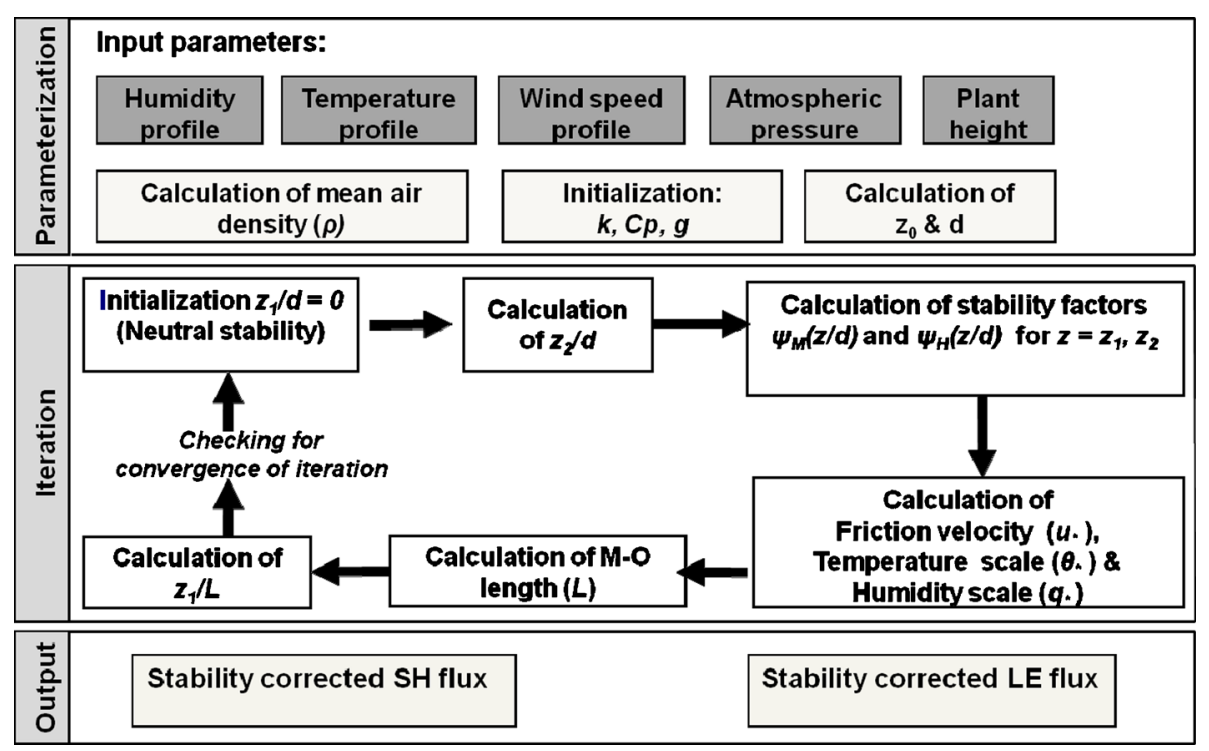

Figure 2. Flowchart showing computational model framework for sensible and latent heat fluxes using MOST. The heights of humidity, temperature and wind speed measurements were $7.5\left(z_{1}\right)$ and $12.5\left(z_{2}\right) \mathrm{m}$. The mean plant height was $6.5 \mathrm{~m}$. $\rho$ is the air density $\left(\mathrm{kg} \mathrm{m}^{-3}\right), k$ is Von-Karman constant, $C p$ is specific heat of the air $\left(\mathrm{J} \mathrm{kg}^{-1} \mathrm{~K}\right), g$ is the acceleration due to gravity $\left(9.8 \mathrm{~m} \mathrm{~s}^{-2}\right), z_{0}$ and $d=$ roughness length and zero plane displacement, respectively. $\Psi_{M}(z / d)$ and $\Psi_{H}(z / d)$ are the integrated momentum stability parameter and integrated stability parameter for heat, respectively. $\theta_{*}=$ temperature scale, $q_{*}=$ humidity scale and $u_{*}=$ frictional velocity (wind scale). $S H$ and $L E$ are sensible and latent heat fluxes. $L$ is Monin-Obukov length.

psychrometric equations. The standard values for specific heat of air $\left(C p=1000 \mathrm{~J} \mathrm{~kg}^{-1} \mathrm{~K}\right)$, and acceleration due to gravity $\left(g=9.81 \mathrm{~m} \mathrm{~s}^{-2}\right)$, latent heat of vaporization of water $\left(\lambda=2.45 \times 10^{6} \mathrm{~J} \mathrm{~kg}^{-1}\right)$ were used. The mean plant height was $6.5 \mathrm{~m}$. The zero plane displacement was computed from plant height using the empirical relation described earlier. The lower and upper heights of humidity, temperature, and wind speed measurements were 7.5 and $12.5 \mathrm{~m}$, respectively. The iterative technique was applied by initializing stability factor $\Psi=1$ and $L=0$ (neutral stability condition). The $u_{*}$ and $\theta_{*}$ were computed following the equations (6) and (7), respectively. Then $L$ was computed from equation (9). Based on the temperature gradient (positive or negative), the iteration was started with stepwise increase or decrease of $L$ following the stable or unstable loop, respectively. The iteration was repeated till the assumed $L$ became nearly equal to the computed $L$ (at 0.001 level of precision). The final value of $L$ was used for the computation of $S H$ and $L E$ flux.

\subsection{Residual energy}

The residual energy for energy balance closure was computed as the difference between net available energy $(Q)$ at surface and sum of sensible and latent heat fluxes from surface.

$$
\text { Residual energy }=Q-(S H+L E) .
$$

\section{Results and discussion}

\subsection{General seasonality of radiation balance components}

The dekadal (10-day) averages of incoming shortwave radiation $(R S \downarrow)$ were found to vary from 116 to $260 \mathrm{Wm}^{-2}$ with annual mean of $178 \mathrm{Wm}^{-2}$. The primary peak of $R S \downarrow\left(260 \mathrm{Wm}^{-2}\right)$ occurred in summer (May1d: first 10 day in May) followed by its decrease during monsoon months and a secondary peak at $200 \mathrm{Wm}^{-2}$ during post-monsoon (Sep3d). Subsequently, the $R S \downarrow$ decreased in winter months (November to January) which varied between 116 and $180 \mathrm{Wm}^{-2}$. In summer months (April to June), the dekadal $R S \downarrow$ varied between 173 and $260 \mathrm{Wm}^{-2}$ with a mean of $229 \mathrm{Wm}^{-2}$. During monsoon (July, August, September), it varied from 130 to $197 \mathrm{Wm}^{-2}$ with a mean of $159 \mathrm{Wm}^{-2}$. Seasonal variability of factors influencing the atmospheric radiative forcing altered the $R S \downarrow$ levels and thereby overall seasonal surface radiation budget. The trend of dekadal average of outgoing shortwave radiation ( $R S \uparrow$ ) from this young growing pine followed a similar trend. The $R S \uparrow$ varied from 12 to $36 \mathrm{Wm}^{-2}$ with a maximum during summer (May1d). It was minimum during monsoon months coincident to low $R S \downarrow$ and higher green vegetation growth and surface wetness.

The dekadal average of outgoing long wave radiation $(R L \uparrow)$ was found to vary from 400 to $500 \mathrm{Wm}^{-2}$ during the study period. The incoming 
long wave radiation $(R L \downarrow)$ was lower than $R L \uparrow$ and was found to vary from 350 to $450 \mathrm{Wm}^{-2}$.

The monthly averages of ratio (albedo) of outgoing to incoming short wave radiative fluxes (table 2) showed the lowest albedo (0.093) in September coincident to maximum wetness and greenness and highest albedo in the month of May (0.135). After the low in September, it gradually increased from October to May and then gradually decreased with the increase in greenness and wetness. The monthly ratio of $R L \uparrow$ and $R L \downarrow$ was found to be more than 1.1 during February to June and in November. However, it became $<1.1$ during the cloudy and wet period in monsoon months (July to October) as well as during the period of thermal inversion leading to foggy conditions in December and January. The monthly ratio of total incoming to total outgoing radiative fluxes was found to be $>1.1$ during February to November but $<1.1$ during December and January, when thermal inversion occurs. The comparison of monthly short wave radiation ratio with that of long wave radiation ratio showed that the former has wider variability than the latter as evident from higher coefficient of variation (table 3 ). The long wave radiation ratio is assumed to be influenced by the temperature gradient as well as emissivity of surface and atmosphere. However, the albedo is a basic surface characteristic with little influence of spectral distribution and angle of incidence of the radiation. The higher long wave radiation ratio (1.130) during April might be due to wider thermal gradient between surface and atmosphere when clear sky condition prevailed. On the other hand, lower long wave radiation ratio (1.031) during August implied comparatively higher incoming long wave radiation possibly from the cloud and water vapour. This signifies the atmospheric influence on the long wave radiation ratio.

Table 2. Mean monthly ratios of various incoming and outgoing radiation components.

\begin{tabular}{lccc}
\hline Months & $\begin{array}{c}\text { Ratio of } R S \uparrow \\
\text { and } R S \downarrow\end{array}$ & $\begin{array}{c}\text { Ratio of } R L \uparrow \\
\text { and } R L \downarrow\end{array}$ & $\begin{array}{c}\text { Ratio of total incoming } \\
\text { and outgoing } \\
\text { radiative fluxes }\end{array}$ \\
\hline January & 0.117 & 1.071 & 1.081 \\
February & 0.115 & 1.105 & 1.148 \\
March & 0.116 & 1.103 & 1.218 \\
April & 0.129 & 1.130 & 1.289 \\
May & 0.135 & 1.116 & 1.313 \\
June & 0.125 & 1.101 & 1.275 \\
July & 0.106 & 1.056 & 1.255 \\
August & 0.102 & 1.031 & 1.266 \\
September & 0.093 & 1.046 & 1.296 \\
October & 0.109 & 1.097 & 1.242 \\
November & 0.119 & 1.101 & 1.171 \\
December & 0.120 & 1.054 & 1.076 \\
Mean & 0.116 & 1.084 & 1.219 \\
SD $( \pm)$ & 0.012 & 0.031 & 0.082 \\
C.V. $(\%)$ & 10.141 & 2.889 & 6.713 \\
\hline
\end{tabular}

Table 3. Mean monthly net radiative fluxes.

\begin{tabular}{|c|c|c|c|c|c|c|}
\hline \multirow[b]{2}{*}{ Months } & \multicolumn{2}{|c|}{$R S_{\text {net }}(\mathrm{SD})$ in $\mathrm{Wm}^{-2}$} & \multicolumn{2}{|c|}{$R L_{\text {net }}(\mathrm{SD})$ in $\mathrm{Wm}^{-2}$} & \multicolumn{2}{|c|}{$R n(\mathrm{SD})$ in $\mathrm{Wm}^{-2}$} \\
\hline & 2010 & 2011 & 2010 & 2011 & 2010 & 2011 \\
\hline January & $134(7)$ & $117(13)$ & $-70(13)$ & $-42(7)$ & $64(6)$ & $75(7)$ \\
\hline February & $151(28)$ & $135(16)$ & $-67(7)$ & $-44(6)$ & $84(30)$ & $91(11)$ \\
\hline March & $190(12)$ & $190(27)$ & $-51(0.66)$ & $-60(9)$ & $139(12)$ & $130(19)$ \\
\hline April & $211(12)$ & $208(25)$ & $-51(2)$ & $-63(9)$ & $160(10)$ & $146(22)$ \\
\hline May & $208(15)$ & $219(7)$ & $-47(2)$ & $-54(7)$ & $161(13)$ & $165(10)$ \\
\hline June & $189(21)$ & $181(39)$ & $-45(0.51)$ & $-30(13)$ & $144(20)$ & $152(27)$ \\
\hline July & $139(23)$ & $156(19)$ & $-25(16)$ & $-18(3)$ & $114(16)$ & $138(17)$ \\
\hline August & $134(31)$ & $147(5)$ & $-14(3)$ & $-16(2)$ & $120(28)$ & $131(4)$ \\
\hline September & $123(53)$ & $162(10)$ & $-19(11)$ & $-24(5)$ & $104(42)$ & $140(5)$ \\
\hline October & $163(10)$ & $156(7)$ & $-41(4)$ & $-39(7)$ & $122(14)$ & $118(10)$ \\
\hline November & $128(16)$ & $114(8)$ & $-41(4)$ & $-48(3)$ & 87 (14) & $82(6)$ \\
\hline December & $108(13)$ & 107 (4) & $-42(6)$ & $-59(10)$ & $65(7)$ & $69(3)$ \\
\hline
\end{tabular}

Values in parentheses indicate \pm standard deviation. 


\subsection{Intra- and inter-seasonal variability of net radiative fluxes}

The dekadal averages of net short wave $\left(R S_{\text {net }}\right)$ and net long wave $\left(R L_{\text {net }}\right)$ radiation over the two years (2010 and 2011) are plotted in figure 3 along with the dekadal cumulative rainfall. Similar to $R S \downarrow$, the $R S_{\text {net }}$ increased during summer months to a peak $\left(230 \mathrm{Wm}^{-2}\right)$ after a low $\left(120 \mathrm{Wm}^{-2}\right)$ in dry winter months (January-February). After the summer peak, it gradually decreased with increase in prevailing wetness and greenness and showed a period of low $R S_{\text {net }}$ in monsoon months (July-September) followed by a secondary peak in September 3rd dekad and decrease with the onset of winter. The magnitude of decrease in $R S_{\text {net }}$ during monsoon months was substantially higher in the higher rainfall year (2010) than 2011 (figure 3a).
The dekadal average of net long wave radiation $\left(R L_{\text {net }}\right)$ showed a low magnitude (figure $3 \mathrm{~b}$ ) of the order of -45 to $-75 \mathrm{Wm}^{-2}$ during the drier period in summer and winter months. It increased and remained between -10 and $-40 \mathrm{Wm}^{-2}$ with the prevalence of cloudy-sky and wet conditions especially in monsoon period. But, the increase was higher in the higher rainfall year of 2010 (2710 mm) than in 2011 (2244 mm).

Figure 3 clearly represents the dekadal (10 days) variations of $R S_{\text {net }}$ and $R L_{\text {net }}$ as influenced by wetness. Consequently, we found these to be strong functions of sunshine hours. The correlation $(r)$ between $R S_{\text {net }}$ and sunshine hours was $0.72\left(R^{2}=\right.$ $0.53, P<0.001 ; n=36)$, however, $r$ between $R L_{\text {net }}$ and sunshine hours was at $0.61\left(R^{2}=0.37\right.$, $P<0.001 ; n=36)$. The monthly means of net short wave and net long wave radiation for 2010 and 2011 are summarized in table 3 .
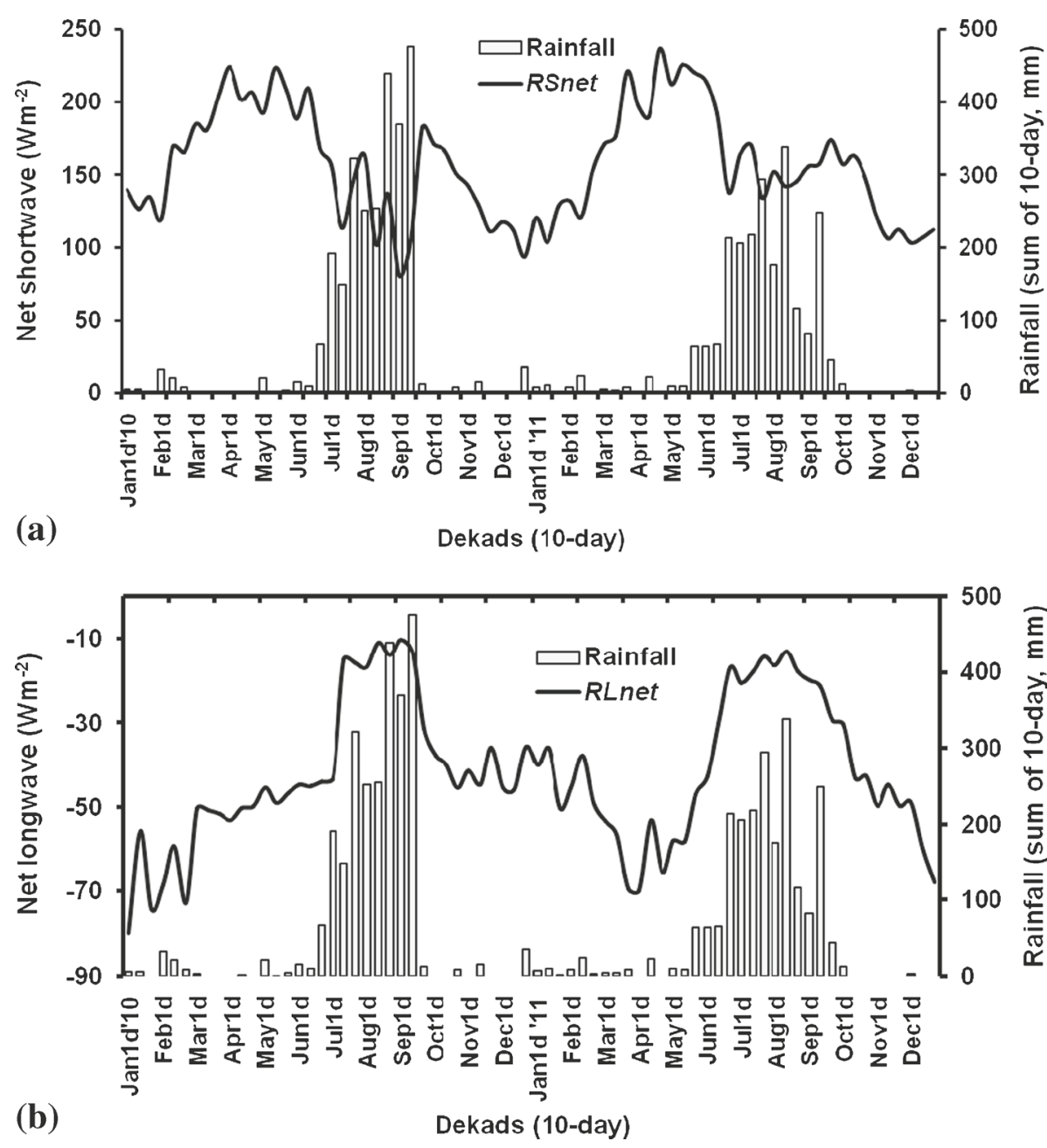

Figure 3. (a) Dekadal variability of net short wave $\left(R S_{\text {net }}\right)$ with rainfall. (b) Dekadal variability of net long wave $\left(R L_{\text {net }}\right)$ with rainfall. 


\subsection{Surface albedo as influenced by GLAI and soil moisture}

The present section describes how seasonal dynamics of two physical controls of energy and mass fluxes namely, albedo (reflected short wave/incident short wave) and surface soil moisture (average of 0-45 cm) are linked to each other in response to seasonal variation of a biophysical control such as green leaf area index (GLAI) in young pine patch. Dekadal (10-day) albedo was found to vary from 0.09 to 0.15 (figure 4 ). It is reported that the range of albedo in pine system was found to be high from 0.1 to 0.34 in Loblolly plantations with age varying between 4 and 25 years having lowering of albedo with increase in age. However, the albedo varied from 0.08 to 0.12 for jack pine, white pine, and slash pine system with age varying between 10 and 65 years (Sun et al. 2010). In the present study, albedo was found to decrease from a peak during May second dekad (e.g., May2d) with the increase in GLAI from 1.75 to 2.5 and soil moisture (highest at $0.23 \mathrm{~m}^{3} \mathrm{~m}^{-3}$ ). Albedo started increasing up to 0.12 from its lowest value in Sept2d to Dec1d when GLAI decreased from 2.5 to 1.3 and soil moisture also decreased from 0.2 to $0.17 \mathrm{~m}^{3} \mathrm{~m}^{-3}$. Subsequently, albedo again showed a decrease up to Feb3d when soil moisture increased due to rainfall, though GLAI was low due to browning and drying of majority of pine needles. Between Mar1d and Apr3d, GLAI was found to increase but with simultaneous increase in albedo. Generally, pine phenology showed $50 \%$ greening during May and reached maximum greening that resulted in higher GLAI driven by higher availability of soil moisture. Simultaneously, understory growth of Lantana and other species took place during this period. With higher pine GLAI, higher background soil wetness, understory green growth absorb more incident solar radiation and cause lesser reflected outgoing short wave radiation from surface leading to low albedo during May to Sep1d. Subsequently, higher proportion of reflected short wave due to low pine GLAI and soil drying led to higher albedo up to Dec3d. When soil exposure to incident solar radiation was more due to low GLAI, albedo showed a decrease due to increase in soil moisture leading to lower proportion of reflected short wave component. The falling of dried pine needles on the ground forms a thin layer of natural mulch on the soil, which increased the background reflectivity and as a result, Lantana and Ageratum growth also subsided. The effect of higher background reflectivity could be seen with the increase in albedo from Mar1d to Apr3d when GLAI started increasing from its lowest value and was low between 1.0 and 1.8. After that, the degradation of natural mulch and growth of green herbaceous understory along with the greening of pine caused lowering of albedo. Therefore, the seasonal variation of albedo, one of the major controls of surface radiation budget could be well explained by the concomitant effect of greenness of pine and its understory, background soil wetness, and background reflectivity.

\subsection{Surface heat fluxes}

Daytime averages of sensible $(S H)$ and latent heat $(L E)$ fluxes were computed over a 10-day period (dekad) from half-hourly fluxes because negligible evapotranspiration generally occurs during nighttime (Leuning et al. 2012). The dekadal daytime $\mathrm{SH}$ was found to vary from 120 to $350 \mathrm{Wm}^{-2}$ during 2010 and from 40 to $300 \mathrm{Wm}^{-2}$ in 2011 with

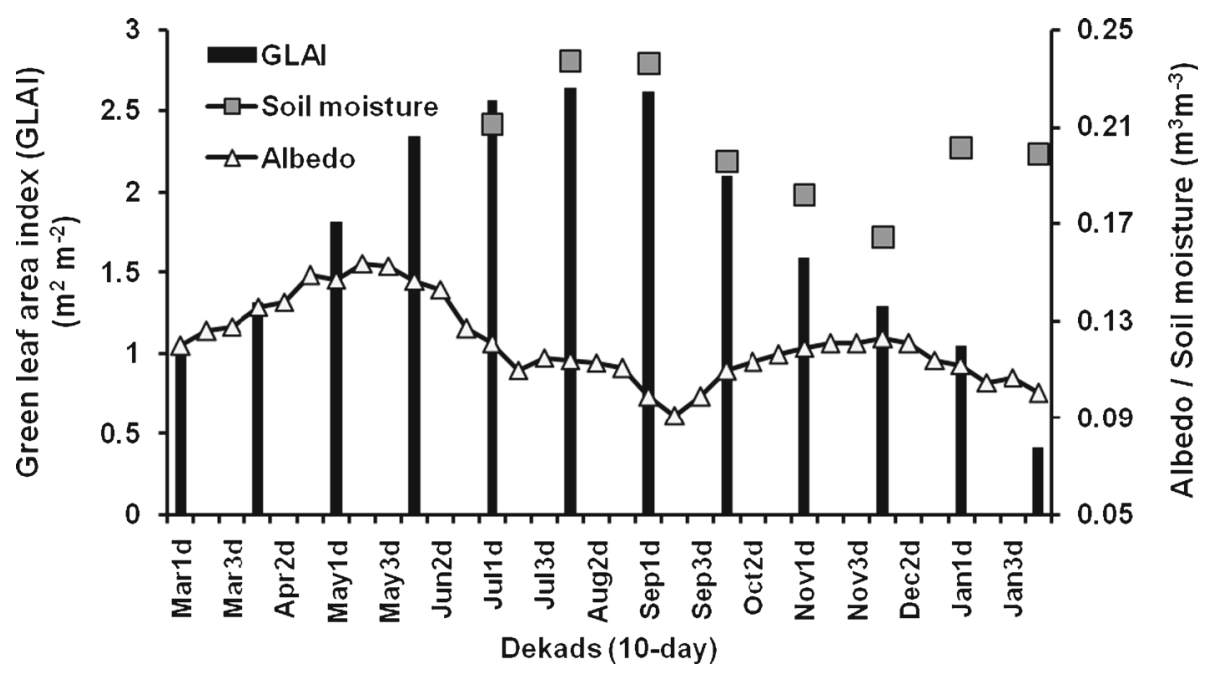

Figure 4. Albedo as influenced by GLAI and soil moisture in chir pine forest. 
the lowest in the December third dekad and highest in May first dekad. A middle order magnitude was noticed during monsoon months when it varied from 150 to $250 \mathrm{Wm}^{-2}$. There was an overall decrease in dekadal $S H$ in 2011 as compared to 2010 (figure 5).

The inter-annual variability of surface heat fluxes ( $S H$ and $L E$ ) is less than inter-seasonal variability. Both $S H$ and $L E$ (figure 5) dropped to minimum levels during winter (Dec1d) when the pine system went into physiologically dormant state. However, sensible heat fluxes were substantially higher than latent heat fluxes during the drier period of winter-summer months when understory species were either cleared or dried to a large extent. The $L E$ increased monotonically during the southwest monsoon and the system reached the stage dominated by evapotranspiration in JulyAugust. This pattern of energy partitioning was noted for both the years. However, some anthropogenic ecosystem manipulations by removing understory vegetations might have some consequent influence on energy partitioning behaviour and thereby on normal ecosystem functioning.

The dekadal daytime latent heat fluxes were found to vary from 40 to $400 \mathrm{Wm}^{-2}$ in 2010 and 20 to $280 \mathrm{Wm}^{-2}$ during 2011 with the highest occurring in the monsoon period (Aug1d) and the lowest in the third dekad of December. Smaller peaks occurred during summer depending on temporal distribution of rain splash. It is interesting to note that both the heat fluxes were of higher magnitude in the year 2010 when there was significantly higher annual rainfall mainly from southwest monsoon as compared to those in 2011. This could be due to spatial and temporal variability of rainfall pattern in this subtropical zone.
Dekadal mean latent heat fluxes were found to produce a significant correlation $\left(R^{2}=0.73\right.$, $P<0.05)$ with dekadal sum of convective rainfall having strong linear fit $(Y=1.348 X-58.27)$. These heat fluxes are major components of surface energy balance. Rainfall in growing chir pine system is the major component of water supply in the so-called water balance. This relation firmly established the strong coupling between energy and water balance specially heat fluxes and rainfall through the response-feedback mechanism in natural vegetative system (figure 6 ).

A further analysis showed that dekadal sensible heat fluxes gradually increased from 250 to $350 \mathrm{Wm}^{-2}$ during pre-monsoon period in 2010 between March1d and June1d and from 220 to $300 \mathrm{Wm}^{-2}$ in 2011. This showed the existence of a possible link between the degree of variability

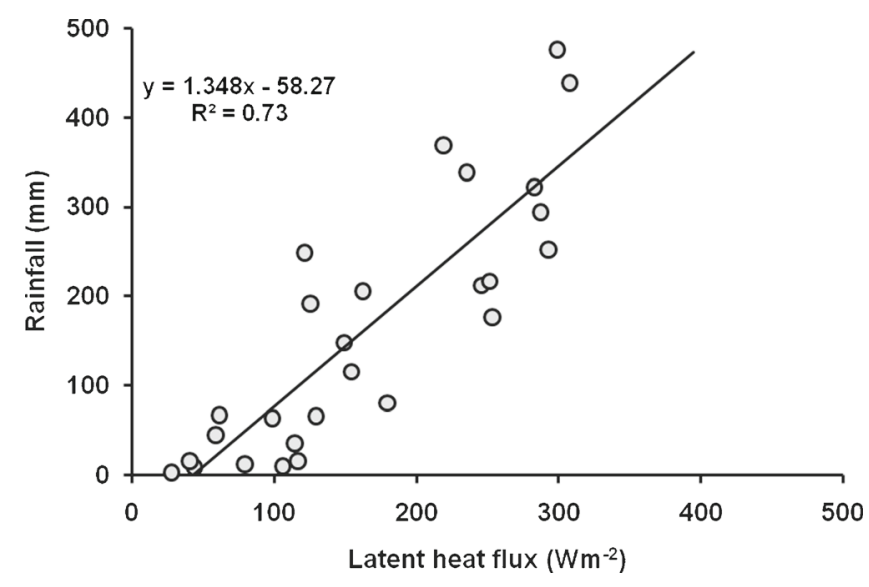

Figure 6. Relationship between dekadal average latent heat fluxes and cumulative rainfall.

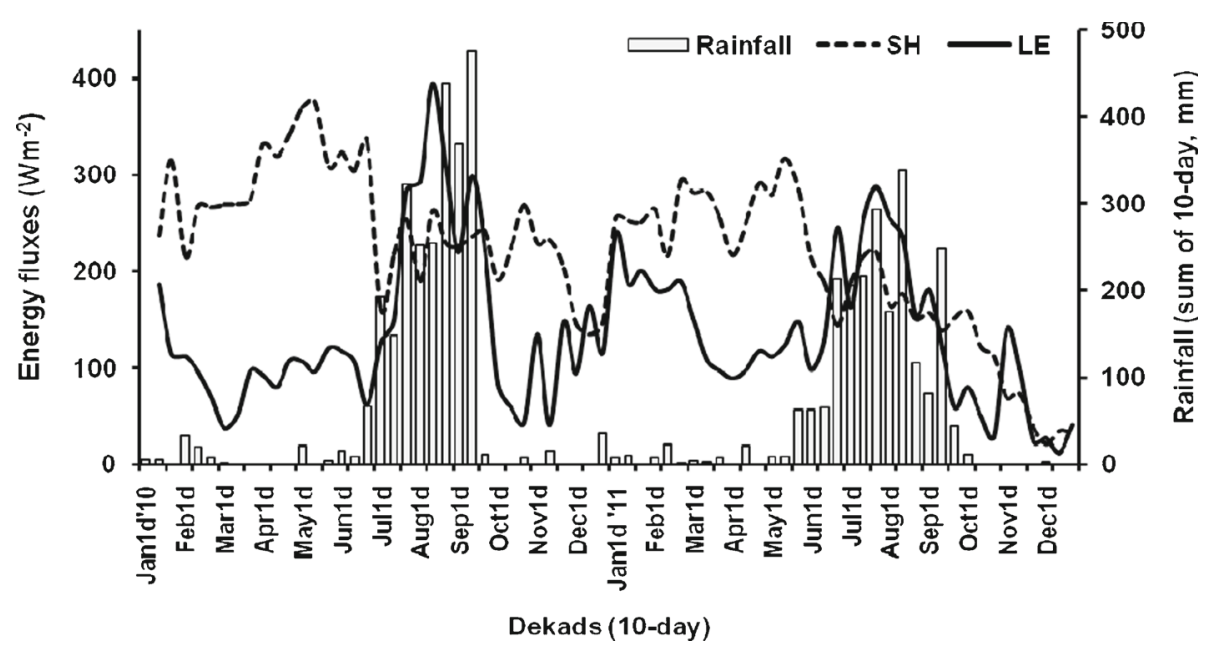

Figure 5. Seasonal variation of dekadal mean of daytime sensible (SH) and latent (LE) heat fluxes over chir pine in two successive years $(2010,2011)$. 
in southwest monsoon rainfall and variability of pre-monsoon sensible heat fluxes (Boos and Kuang 2010; Wu et al. 2012). The monsoon rainfall in the Doon valley is majorly convective in nature and partly influenced by orography. It is highly possible that pre-monsoonal convective heat fluxes (sensible heat flux) over the subtropical pine system in the western Himalaya can influence convective rain during southwest monsoon period thereby modulating the magnitude of rainfall (Dey and Bhanukumar 1983; Andre et al. 1989; Garrat 1992; Turner and Annamalai 2012). However, this could be substantiated only through long-term analysis of sensible heat fluxes.

Coniferous trees such as pine, in general, have a clear annual cycle of photosynthetic activity, the rate of assimilation is low or zero in the winter, increases during the spring, peaks in AugustSeptember followed by a decline in the autumn (Pelkonen and Hari 1980; Bergh and Linder 1999; Makela et al. 2004; Kolari et al. 2007). In this study also, the seasonal transition of fraction of latent heat flux to net radiation $(L E / R n)$ follows the growth curve (figure 7 ) of green vegetation fraction (GVF). But, a time lag was found between the start of greening and increase in latent heat flux. Moreover, the persistence in peak GVF and peak $L E$ fraction differed. The former has a longer latency period than the latter. Further, conservative water use in conifers is an inherent physiological property. Summer environmental stresses with high VPD must have regulated stomatal and canopy conductance of newly emerged needles thus affecting $L E$ fluxes (Launiainen 2010). The differential response of hormonal regulation immediately after dormancy break and before dormancy might have differentially influenced the occurrence of greenness and root water uptake as well as its rate of transpirational loss affecting $L E$ flux (Arneth et al. 2006; Sevanto et al. 2006). The $L E$ fraction more than 1.0 (the energy balance closure issues are discussed in next section) could be associated with wet canopy evaporation (Watanabe and Mizutani 1996) along with local advections. Tchebakova et al. (2002) showed that in boreal coniferous ecosystem, in early spring, in the absence of physiological activity, a large fraction $(\sim 80 \%)$ of available energy is partitioned into sensible heat and Bowen ratio exceeded 8 in a Siberian Scots pine forest. Within the following weeks, associated with recovery of photosynthetic capacity, the transpiration rates rapidly increased and $S H$ dropped. Similar responses were also noted by Arneth et al. (2006) in these coniferous systems.

\subsection{Energy balance closure (EBC)}

The energy balance closure (EBC) behaviour of growing chir pine system encompassing different seasons was evaluated through 1:1 plot (figure 8a) between available energy and surface heat fluxes (sum of sensible and latent heat fluxes from MOST approach). The slope of the linear regression between available energy and turbulent fluxes was about $0.66(r=0.56)$. A plot of dekadal residual energy for the years 2010 and 2011 is shown in figure $8(\mathrm{~b})$. The monthly energy balance residuals along with phenological stages of chir pine and monthly total rainfall are shown in table 4 . There was marked seasonality in EBC with poor closure during southwest monsoon and physiologically dormant winter months of 2010 coincident with forced clearance of understory species compared to spring-summer and autumn, when

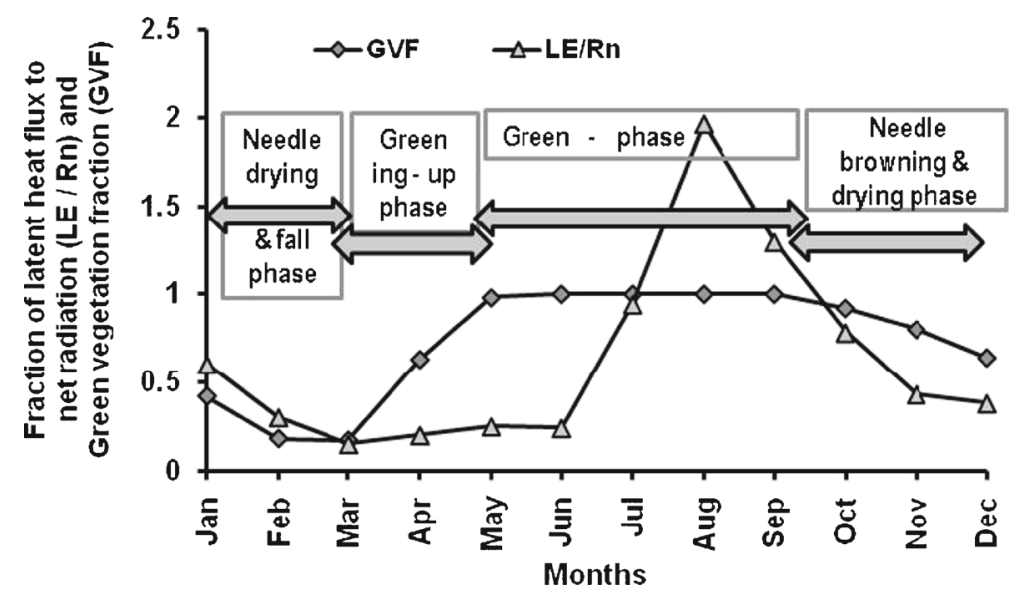

Figure 7. Seasonal transition of fraction of latent heat flux and green vegetation fraction. 

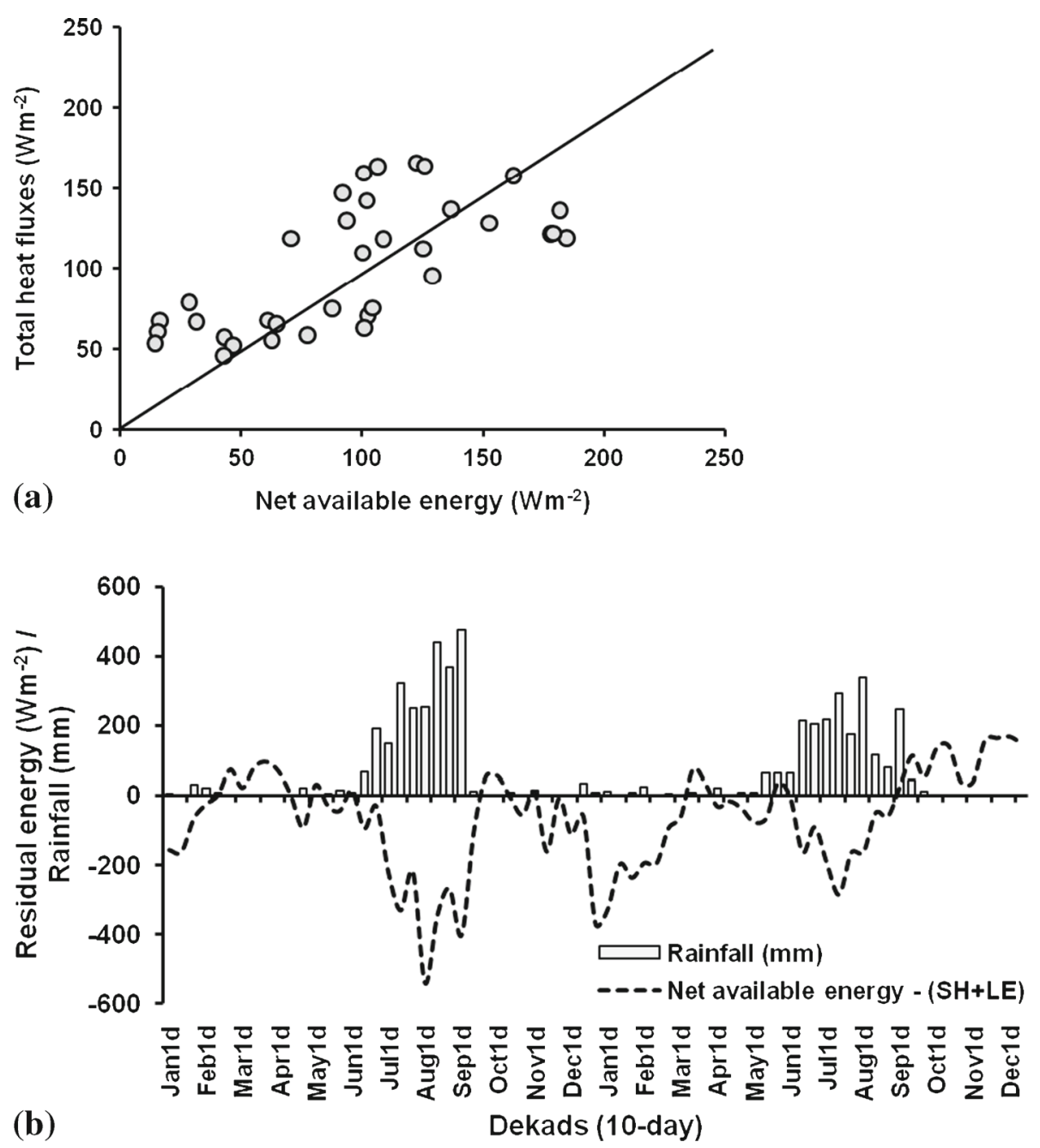

Figure 8. (a) Net available energy vs. total (sensible+latent) heat fluxes from aerodynamic approach. (b) Dekadal variability of residual energy with rainfall.

rainfall was substantially less. During winter of 2011, when understory was present EBC was better (figure 8b). Launiainen (2010) also observed a similar but somewhat better pattern in energy closure in his inter-annual experiment in boreal coniferous forest. Other authors working in different terrestrial ecosystems, forests in particular (Wilson et al. 2002; Grunwald and Bernhofer 2007; Foken 2008; Moderow et al. 2009) found EBC in the range of $50 \%-95 \%$.

Wilson et al. (2002) documented that a lack of closure with $20 \%$ missing energy was not uncommon in the FLUXNET. In the present study, working with slow response sensors and with aerodynamic approach (MOST), sources of imbalances in EBC and seasonal variability could be many. Though percent residual of net available energy varied to a large extent throughout the year, it mostly lies within $\pm 30 \%$. Most of the time in the annual cycle, EBC remains on the negative side (figure 8b), indicative of energy-limited regime.
This might be due to high evapotranspiration requirement of the young and actively growing chir pine system where the latent heat requirement was supplemented by the advective heat flow from the nearby open field.

The surface energy balance is seldom closed by the micrometeorological measurements. The mismatch may originate from various reasons including: measurement inaccuracies, missing data, lack of air turbulence, heterogeneity of landscape, and non-inclusion of storage terms (Restrepo and Arain 2005). However, in a recent review by Foken (2008), these 'classical' explanations for residual of energy balance were suggested to be of secondary importance as compared to larger-scale processes. Foken (2008) brought up the importance of the contribution of large eddies on surface-atmosphere exchange and hypothesized the energy balance to be closed only at landscape scale $(>1 \mathrm{~km})$, not at the micrometeorological scale $(<1 \mathrm{~km})$ through flux towers. Although a detailed scrutiny of the 
Table 4. Monthly mean of residual energy balance along with different phenological stages.

\begin{tabular}{|c|c|c|c|c|c|}
\hline \multirow[b]{2}{*}{ Months } & \multirow[b]{2}{*}{ Phenological stages of chir pine } & \multicolumn{2}{|c|}{$\begin{array}{c}\text { Mean residual energy } \\
\text { as a per cent of net } \\
\text { available energy }\end{array}$} & \multicolumn{2}{|c|}{$\begin{array}{l}\text { Monthly sum of } \\
\text { rainfall }(\mathrm{mm})\end{array}$} \\
\hline & & 2010 & 2011 & 2010 & 2011 \\
\hline January & Drying needles & -60 & -224 & 10.3 & 17.5 \\
\hline February & Drying needles & -11 & -92 & 60.5 & 33 \\
\hline March & Drying and new emerging needles & 15 & -9 & 1.7 & 15 \\
\hline April & New emerging needles & 11 & -1 & 0.5 & 21.1 \\
\hline May & Elongating needles & -8 & -16 & 25 & 80.5 \\
\hline June & Emerged green needles & -13 & -21 & 90.6 & 341 \\
\hline July & Green needles & -108 & -78 & 661 & 716 \\
\hline August & Green needles & -242 & -50 & 315 & 630 \\
\hline September & Green needles & -161 & 8 & 857 & 374 \\
\hline October & Start of degreening of needles & 10 & 37 & 8.3 & 12 \\
\hline November & Green and degreening needles & -33 & 35 & 15.4 & 0 \\
\hline December & Degreening and drying needles & -31 & 74 & 34.9 & 2.7 \\
\hline
\end{tabular}

reasons of unclosed energy balance is beyond the scope of this paper, a few findings merit discussion. It has been found in the present study that residual energy during a major part of the observation period was negative. During the rainy period, the magnitude of negative residual energy is very high. It is interesting to note that the change in radiative energy gain (net radiation) during rainy period varied in the range of $123-162 \mathrm{Wm}^{-2}$ (table 3 ) as compared to $190-219 \mathrm{Wm}^{-2}$ during the dry months, whereas the residual energy varied around -200 to $-500 \mathrm{Wm}^{-2}$ during the rainy period. During the rest of the period, it is either positive or near zero. This implies the contribution of a secondary source of energy flow to the net energy balance of the chir pine system. Removal of understory species in November 2009 and 2010 and time lag between its reappearance could cause poorer energy closure during winter of 2009 and 2010. Further, EBC was on the positive side when undergrowths were not removed during winter of 2011. During the rainy period, the actively growing pine is being supplied with ample moisture from deeper layers of soil whereas the surrounding open land surface dried quickly after each rain event. The adjacent open land is the potential source of advective heat to maintain the high latent heat flux from the chir pine stand. This would lead to the negative residual energy during rainy period. However, the conservative nature of evapotranspiration of needle-leaved chir pine species during the dry period did not favour such an 'oasis effect'. Therefore, any quick and repeated disturbances like rain splashing are expected to disrupt equilibrium as well as energy balance in the forest system. However, the magnitude of advective impact decreased more in 2011 than in 2010 as evident in the figure (8b), with progressive understory growth and rainfall variations.
A critical analysis of the result suggests that wherever there is good energy closure, the period can be characterized by low sensible fluxes, dynamic (not consistent) cloudy conditions, some pre-monsoon, scattered wet spells coupled with dry spells and hence shallow ABL (Atmospheric Boundary Layer) and significantly better EBC. Also Lindroth et al. (2010) found that energy balance residual increased in strongly unstable conditions above a mixed coniferous forest in Sweden. It can be noted in the present study that in both the years, the monthly residual energy balance (table 4) showed higher magnitude during rainspells irrespective of phenological stages. This supports the earlier findings of Makela et al. (2004), Arneth et al. (2006), and Hari and Kulmala (2008).

\section{Conclusions}

The present paper reports for the first time the dynamics of radiation and heat flux behaviour in a growing chir pine system in western Himalayas and the role of understory species on energy balance closure from two years of observations. Seasonal variability of latent heat fluxes from evapotranspiration is in tandem with rainfall variability. This showed a strong coupling of energy balance with water budget in a natural vegetative system. This study clearly brought out the intimate link of albedo dynamics in chir pine system with dynamics of LAI, soil moisture, and changes in understory background. Complete removal of understory can disturb the surface energy balance. The study also brought out the existence of a possible link between degree of variability in 
southwest monsoon rainfall and variability of premonsoon sensible heat fluxes. The monsoon rainfall in the Doon valley is majorly convective in nature and partly influenced by orography. Thus, it is highly possible that pre-monsoonal convective heat fluxes (sensible heat flux) over the subtropical pine system in the western Himalaya can influence monsoonal circulation thereby modulating magnitude of rainfall. In future, long-term measurements and analysis can be carried out in other Himalayan regions where large patches of similar coniferous vegetation exist for validation of this possible link. Proper evapotranspiration estimates in coniferous forests would aid in addressing many issues in studying the role of such forest systems in regulating landscape hydrology and bio-geochemistry.

\section{Acknowledgements}

This work has been carried out under the project titled 'Energy and Mass Exchange in Vegetative Systems (EME-VS)' in ISRO Geosphere Biosphere Programme. The first and fourth authors are grateful to Director, Forest Research Institute, Dehradun, India for his encouragement to carry out this work. The second and fifth authors are thankful to Director, Space Applications Centre (ISRO) for providing the necessary support. The second author is indebted to Dr Sushma Panigrahy, Group Director, ABHG/SAC (ISRO) for providing time-to-time advice.

\section{References}

Andre J C, Bougeault P, Mahfouf J F, Mascart P, Noilhan $\mathrm{J}$ and Pinty J P 1989 Impact of forests on mesoscale meteorology; Phil. Trans. Roy. Soc. Series B 324 407422.

Arneth A, Lloyd J, Shibistova O, Sogachev A and Kolle O 2006 Spring in the boreal environment: Observations on pre- and post-melt energy and $\mathrm{CO}_{2}$ fluxes in two central Siberian ecosystems; Bor. Env. Res. 11 311-328.

Beljaars A C M and Holstag A A M 1991 Flux parameterization over land surface for atmospheric models; J. Appl. Meteorol. 30 327-341.

Bergh J and Linder S 1999 Effects of soil warming during spring on photosynthetic recovery in boreal Norway spruce stands; Global Change Biol. 5 245-253.

Betts R A 2001 Biogeophysical impacts of land use on present-day climate: Near-surface temperature change and radiative forcing; Atmos. Sci. Lett. 2 39-51.

Bhatt Y D, Rawat Y S and Singh S P 1994 Changes in ecosystem functioning after replacement of forest by Lantana shrubland in Kumaun Himalaya; J. Veg. Sci. 5 67-70.

Bhattacharya B K, Gunjal K, Nanda M and Panigrahy S 2009 Protocol development of energy-water flux computation from INSAT-linked micrometeorological station and model development; SAC/RESA/ARG/ EMEVS/SR/02/2009, Chapter 3, pp. 34-53.
Bonan G 2008 Forests and climate change: Forcings, feedbacks and the climate benefits of forests; Science $\mathbf{3 2 0}$ 1444-1449.

Boos W R and Kuang Z 2010 Dominant control of the south Asian monsoon by orographic insulation versus plateau heating; Nature 463 218-222.

Businger J A, Wyngaard J C, Izumi I and Bradley E 1971 Flux-profile relationships in the atmospheric surface layer; J. Atmos. Sci. 28 181-189.

Campbell G S and Norman J M 1998. Introduction to Environmental Biophysics; Springer Science + Business Media, Inc, NY, USA, 71p.

De Bruin H A R, Ronda R J and Van De Weil B J H 2000 Approximate solution for the Obukhov length and surface fluxes in terms of bulk Richardson numbers; Bound.-Layer Meteorol. 95 145-157.

Dey B and Bhanukumar O S R U 1983 The Himalayan winter snow cover and summer monsoon rainfall over india; J. Geophys. Res. 88 5471-5474.

Dobhal P K, Kohli R K and Batish D R 2011 Impact of Lantana camara $\mathrm{L}$. invasion on riparian vegetation of Nayar region in Garhwal Himalayas (Uttarakhand, India); J. Ecol. Nat. Environ. 3(1) 11-22.

Dyer A J 1974 A review of flux-profile relationships; Bound.Layer Meteorol. 7 363-372.

Foken T 2008 The energy balance closure problem: An overview; Ecol. Appl. 18(6) 1351-1367.

FSI 2011 Indian State of Forest Report 2011; Forest Survey of India, Ministry of Environment and Forests, Government of India, Dehra Dun, India.

Garrat J R 1992 The Atmospheric Boundary layer; Cambridge University Press, Cambridge.

GBPIHED 2009-2010 Annual Report 2009-10. G.B. Pant Institute of Himalayan Environment \& Development (GBPIHED); (An Autonomous Institute of Ministry of Environment, Forests and Climate Change, Government of India), Kosi-Katarmal, Almora-263643, Uttarakhand, India, http://gbpihed.gov.in.

Grunwald T and Bernhofer C 2007 A decade of carbon, water and energy flux measurements of an old spruce forest at the Anchor Station Tharandt; Tellus $B \mathbf{5 9}$ 387-396.

Hari P and Kulmala L 2008 Boreal Forest and Climate Change; Springer, ISBN: 978-1-4020-8717-2.

Kimothi M M, Anitha D, Vasistha $\mathrm{H}$ B, Soni $\mathrm{P}$ and Chandola S K 2010 Remote sensing to map the invasive weed, Lantana camara in forests; Trop. Ecol. 51(1) $67-74$.

Kolari P, Lappalainen H, Hanninen H and Hari P 2007 Relationship between temperature and the seasonal course of photosynthesis in Scots pine at northern timberline and southern boreal forest; Tellus B 59 542-552.

Launiainen S 2010 Seasonal and inter-annual variability of energy exchange above a boreal Scots pine forest; Biogeosci. Discuss. 7 6441-6494.

Leuning R, Gorsela E V, Massmanb W J and Isaacc P R 2012 Reflections on the surface energy imbalance problem; Agric. For. Meteorol. 156 65-74.

Lindroth A, Molder M and Lagergren F 2010 Heat storage in forest biomass improves energy balance closure; Biogeosci. 7 301-313.

Makela A, Hari P, Berninger F, Hanninen H and Nikinmaa E 2004 Acclimation of photosynthetic capacity in Scots pine on the annual cycle of temperature; Tree Physiol. 24 369-378.

Moderow U, Aubinet M, Feigenwinter C, Kolle O, Lindroth A, Molder M, Montagnani L, Rebman C and Bernhofer C 2009 Available energy and energy balance closure at four coniferous sites across Europe; Theor. Appl. Climatol. 98 397-412. 
Norman J M and Gower S T 1990 Rapid estimation of leaf area index in forest using the LI-COR LAI-2000; Ecology 72(5) 1896-1990.

Pelkonen P and Hari P 1980 The dependence of springtime recovery of $\mathrm{CO}_{2}$ uptake in Scots pine on temperature and internal factors; Flora $\mathbf{1 6 9} 398$ 404.

Rach O A, Wilkes B H and Sachse D 2014 Delayed hydrological response to Greenland cooling at the onset of the Younger Dryas in western Europe; Nature Geosci., doi: $10.1038 /$ ngeo2053.

Rawat L 2012 Trends of winter rainfall at new forest, Dehradun during last eight decades; The Indian Forester 138(4) 396-397.

Restrepo N C and Arain M A 2005 Energy and water exchanges from a temperate pine plantation forest; Hydrol. Process 19 27-49.

Ryan M G and Yoder B J 1997 Hydraulic limits to tree height and tree growth; Biosci. 47 235-242.

Sevanto S, Suni T, Pumpanen J, Gronholm T, Kolari P, Nikinmaa E, Hari P and Vesala T 2006 Winter-time photosynthesis and water uptake in a boreal forest; Tree Physiol. 26 749-757.

Singh J S and Singh S P (eds) 1992 Forests of Himalaya: Structure, Functioning and Impact of Man; Gyanodaya Prakashan, Nainital, India.

Singh J S, Singh S P and Gupta S R (eds) 2006 Ecology Environment and Resource Conservation; Anamaya Publishers, New Delhi, India, 90p.

Sun G, Noormets A, Gavazzi M J, Mcnulty S G, Chen J, Domec J C, King J S, Amatya D M and Skaggs R W 2010 Energy and water balance of two contrasting loblolly pine plantations on the lower coastal plain of North Carolina USA; For. Ecol. Manag. 259 1299-1310.

Tchebakova N M, Kolle O, Zolotoukhine D, Arneth A, Styles J M, Vygodskaya N N, Schultze E D, Shibistova O and Lloyd J 2002 Inter-annual and seasonal variations of energy and water vapour fluxes above a Pinus sylvestris forest in Siberian middle taiga; Tellus B $\mathbf{5 4} 537-551$.

Thom A S 1975 Momentum, mass and heat exchange of plant community; In: Vegetation and the atmosphere (ed.) Monteith J L, Academic Press, pp. 57-109.

Turner A G and Annamalai H 2012 Climate change and the south Asian summer monsoon; Nature Climate Change $\mathbf{2}$ $587-595$.

Verma S B 1990 Micrometeorological methods for measuring surface fluxes of mass and energy; Remote Sens. Rev. 5 99-115.

Watanabe T and Mizutani Kanji 1996 Model study on micrometeorological aspects of rainfall interception over an evergreen broad-leaved forest; Agric. For. Meteorol. 80 195-214.

Wilson K, Goldstein A, Falge A, Aubinet M, Baldocchi D, Berbigier P, Bernhofer C, Ceulemans R, Dolman H, Field C, Grelle A, Ibrom A, Law B E, Kowalski A, Meyers T, Moncrieff J, Monson R, Oechel W, Tenhunen J, Valentini R and Verma S B 2002 Energy balance closure at FLUXNET sites; Agric. For. Meteorol. 113 223-243.

Wu G, Liu Y, He B, Bao Q, Duan A and Jin F F 2012 Thermal controls on the Asian summer monsoon; Sci. Rep. 2404.

Xu Q and Qiu C J 1997 A variational method for computing surface heat fluxes from ARM surface energy and radiation balance systems; J. Appl. Meteor. 36 4-11. 